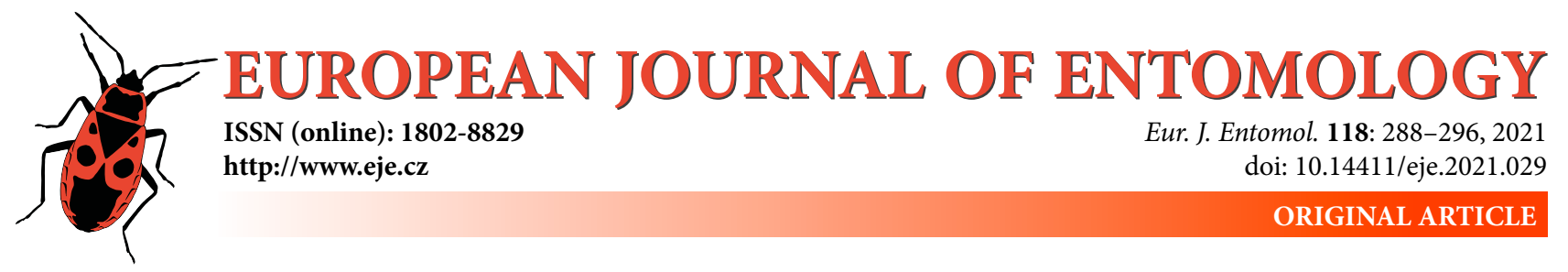

\title{
Assessing year-round phenology and reproduction of the migratory painted lady butterfly, Vanessa cardui (Lepidoptera: Nymphalidae), in a Mediterranean area in southern Spain
}

\author{
MARIANO CUADRADO (iD) \\ Departamento Técnico, ZooBotánico de Jerez - Ayuntamiento de Jerez, Madreselva s/n, E-11408 Jerez de la Frontera (Cádiz), \\ Spain; e-mail: mc.macuagu@gmail.com
}

Key words. Lepidoptera, Nymphalidae, Vanessa cardui, migratory butterflies, phenology, winter reproduction, Mediterranean area, Spain

\begin{abstract}
The painted lady, Vanessa cardui (Linnaeus, 1758), migrates seasonally between Africa and Europe with a northward multigenerational migration from Africa to Europe in spring and a southward migration from Europe to Africa in autumn. However, little is known about the year-round phenology of this species in southern regions in the Mediterranean Basin. In this study the year-round phenology and reproduction of painted ladies was recorded during a seven-year period (2014-2020) at 7 lowland sites (< $80 \mathrm{~m}$ a.s.I) near the coast of Cádiz (southern Spain). Overall, a total of 2341 painted lady butterflies (or 0.56 butterflies/ $\mathrm{km}$ ) were recorded along $4186 \mathrm{~km}$ of transects of the Butterfly Monitoring Scheme (BMS). Data pooled for all sites and years indicate a migration of painted ladies in autumn (mid and late October), another peak in abundance in winter (late February) and finally a migration in spring (late May). Abundance, however, varied greatly between sites and years. In July 2019, a spectacular migration of painted ladies was recorded across the study area that was also recorded in other European countries a few weeks later. Territorial behaviour of males, including hill-topping and courtship, oviposition and immature stages were recorded in autumn and winter. Reproductive behaviour was not recorded in spring or summer. Painted ladies were most abundant during the autumn migration, less abundant in spring and much less abundant in winter. This study confirms that the southern tip of Western Europe close to North Africa is an important stop-over region during the migration of painted ladies although numbers fluctuate enormously between years and sites. To my knowledge, this is the first time that the timing of year-round migration and the reproduction of painted ladies in the autumn-winter months have been described for a southern European population.
\end{abstract}

\section{INTRODUCTION}

Every year, large numbers of many species of butterflies undertake seasonal movements that are considered to be true migrations (Williams, 1930, 1957). Unlike the twoway migrations often regarded as characteristics of vertebrate migrations, individual insects do not make roundtrips bringing them back to the area from which they departed. Instead, individuals of different generations take part in a multi-generational migratory movement (i.e. the offspring of a generation continues the migration trip for breeding purposes or to reach wintering sites (e.g. Chapman \& Drake 2010; Chowdhury et al., 2021; Holland et al., 2006; Hu et al., 2021).

The painted lady, Vanessa cardui, is a well-known butterfly with a worldwide distribution (for an overview, see Opler \& Krizek, 1984; Bitzer, 2016) and multigenerational long-distance migrations. In the Palearctic, large numbers of painted ladies undertake seasonal movements between Africa and Europe, with a northward migration from Africa to Europe in spring and a southward migration from
Europe to Africa in autumn (Pollard et al., 1998; Stefanescu et al., 2011, 2016, 2021; Talavera \& Vila 2016; Talavera et al., 2018; Comay et al., 2020). Between 6-10 different generations are thought to be involved in an annual migratory loop of about 12,000-14,000 km between tropical West Africa and Scandinavia, which is the longest regular insect migration circuit currently known (Stefanescu et al., 2013; Menchetti et al., 2019; Hu et al., 2021).

Recently, a number of studies have reported some important cues for the migratory habits of this species in the Palearctic. First, Stefanescu et al. (2017) report the complete absence of this species in North Africa (Morocco and Algeria) at the end of summer (mid-to-late September) followed by the arrival of huge numbers of migrants in October and early November. Isotopic analyses of butterfly wings confirm that most of these migrants come from $\mathrm{Eu}-$ rope although there is also a significant immigration from the Sahel region (Stefanescu et al., 2016).

Secondly, some field studies report both the presence of painted ladies in the Maghreb region in winter (Stefanescu 
et al., 2013) and breeding both in the Maghreb and subSaharan region prior to the northward migration in spring (Stefanescu et al., 2011, 2013; Talavera et al., 2018). In spring, the finding of pollen grains of tropical origin on the proboscis of migrating painted ladies also confirms their sub-Saharan origin (cf. Suchan et al., 2019). The arrival of these migrants in the Mediterranean region occurs in a number of successive waves from February to June-July (cf. Stefanescu et al., 2007; Talavera et al., 2018; Hu et al., 2021).

Thirdly, winter breeding areas (the so-called "the winter missing generation" cf. Benyamini, 2017) have not been identified (cf. Talavera \& Vila, 2016; Menchetti et al., 2019; but see Benyamini, 2017 for a report for Israel) probably due to variable densities and localities in relation to unpredictable rainfall.

Fourthly, while the spring migration of painted ladies from Africa to Europe is well documented, field evidence for the autumn migration of painted ladies is surprisingly scarce in the literature (e.g. Nesbit et al., 2009; Talavera \& Vila, 2016). To my knowledge, the only available evidence is based upon an autumnal radar study of the Palearctic by Stefanescu et al. (2013).

To summarize, available evidence indicates that painted ladies exploit the resources available in temperate regions in Europe and North Africa from March to September October and tropical regions in sub-Saharan Africa from September to March (Stefanescu et al., 2013; Talavera \& Vila, 2016; Talavera et al., 2018, Hu et al., 2021). Little is known about the year-round phenology of this species in southern sites around the Mediterranean Basin. In this study, the year-round phenology of painted ladies butterflies was recorded at several lowland sites close to Cádiz (southern Spain) during a 7-year period. The aims of this study are three. First, to determine the year-round phenology of butterflies in the area. Second, from the seasonal abundance of butterflies, to determine the dates when migration occurred. According to the migratory pattern referred to above, one could expect two peaks of abundance, one in spring and another in autumn. Further, available evidence suggests that the migration peak should be higher in spring than during autumnal migration (cf. p. 8 in Comay et al., 2020 for Israel). And third, to record the reproductive behaviour of the species in this area. The location of the study area, at the southern tip of Western Europe, close to North Africa, is important for understanding the migratory strategy of this and other species of butterflies. To my knowledge, this is the first time that these aspects have been studied at a Mediterranean site in southern Europe.

\section{MATERIALS AND METHODS}

\section{Butterfly counts}

Standard transect counts (Butterfly Monitoring Scheme, van Swaay et al., 2012) were used to record adult abundance. The transect method was used to record the number of butterflies seen by the observer in a volume of space $(5 \mathrm{~m}$ width or $2.5 \mathrm{~m}$ on both sides; $5 \mathrm{~m}$ high and $5 \mathrm{~m}$ in front of the observer) while walking slowly along the transect. The local time, ambient temperature, cloud cover (on a scale of 0 to 8 ) and wind speed (using $0-5$ on the Beaufort scale) were noted first at the beginning and then at the end of the transect (cf. Van Swaay et al., 2012). Counts were made between $10 \mathrm{am}$ and $7 \mathrm{pm}$ local time on days with no rain and an ambient temperature of $>13^{\circ} \mathrm{C}$. As some activities (e.g. territorial behaviour and mating) are restricted to late afternoon (cf. Brown \& Alcock, 1990; M. Cuadrado, pers. observ., see below), a special effort was made to sample during the afternoon throughout this study. For this study, it was not necessary to capture any specimens. When necessary, $10 \times 40$ Zeiss binoculars were used to identify individual butterflies at a distance.

\section{Study sites}

The year-round BMS butterfly counts were carried out at 7 plots located around the Bay of Cadiz (Cádiz, southern Spain). Each plot was visited 1-5 times a month (sometimes more) throughout the year (from January to December). All sites studied were located at low altitudes $(<80 \mathrm{~m}$ a.s.l., distance between sites $<25 \mathrm{~km}$ ) near the Atlantic coast. The climate in the area is typically Mediterranean with hot summers and mild winters. It rains mainly during autumn and winter, with little rain in summer. However, due to the low altitude and the proximity to the sea, both winter and summer temperatures are less extreme than is typical for this climate. Technically, the climate is defined as "sea-influenced Mediterranean climate" or "Mediterráneo submarítimo" (cf. Font Tullot, 1983).

At each plot studied, transects (total distance ranged between $470 \mathrm{~m}-2.6 \mathrm{~km}$ in length) were established at the most favourable sites for butterflies. Following the BMS methodology, each transect was divided into $2-8$ sections $(100-800 \mathrm{~m}$ each). The characteristics of the plots and the period over which the field work was carried out were as follows:

1. Jerez (Jerez de la Frontera, Cádiz, 36.689009, -6.150112). This study area was located in the gardens of ZooBotánico Jerez, a zoological park ( 6.5 ha in size) located in the western part of the city of Jerez. The whole area is surrounded by roads and buildings. To perform the BMS censuses, a $2 \mathrm{~km}$ transect was established and divided into 8 sections (200-350 m each). Field work was carried out 1-7 days per week. Standard BMS censuses (see above), were carried out from January 2014 to December 2020. The total distance covered in the BMS censuses was $2,206 \mathrm{~km}$ ( 290 in 2014, 310 in 2015, 354 in 2016, 312 in 2017, 302 in 2018, 362 in 2019 and 276 in 2020).

2. Punta del Boquerón (Parque Natural Bahía de Cádiz, 36.407491, -6.218390, San Fernando, Cádiz). This study area is a nature reserve located on the sea shore, $4 \mathrm{~km}$ south from the city of San Fernando. The transect ( $2.6 \mathrm{~km}$ long) was linear and divided into $6(300-800 \mathrm{~m})$ sections that extended in a NW-SE direction, parallel to the seashore. BMS censuses were carried out at least twice a month, from June 2014 to December 2020. The total distance covered in the BMS censuses was $978 \mathrm{~km} \mathrm{(31} \mathrm{in}$ 2014, 91 in 2015, 197 in 2016, 187 in 2017, 140 in 2018, 174 in 2019 and 156 in 2020).

3. Botánico (Jardín Botánico de San Fernando, San Fernando, Cádiz, 36.472522, -6.201534). This study area is a typical botanical garden (1.2 ha in size) situated in the western part of the city of San Fernando. To carry out the BMS censuses, a $0.97 \mathrm{~km}$ transect was established and divided into 6 sections (between 100 and $200 \mathrm{~m}$ each). BMS censuses were carried out at least once a month from July 2014 to July 2020 . The total distance covered in the BMS censuses was $228 \mathrm{~km}$ ( 9 in 2014, 26 in 2015, 66 in 2016, 47 in 2017, 35 in 2018, 37 in 2019 and 6 in 2020).

4. Camposoto (San Fernando, Cádiz, 36.441724,-6.2265352). This study plot ( $2.2 \mathrm{ha})$ is a rural track named "Sendero Salina Tres Amigos" in Parque Natural Bahía de Cádiz, $3 \mathrm{~km}$ south from the city of San Fernando. The transect was linear (length $=0.72$ 
$\mathrm{km}$ ) and divided into 4 sections (between 130 and $230 \mathrm{~m}$ each). Field work was carried out at least once a month from November 2015 to December 2020. The total distance covered in the BMS censuses was $310 \mathrm{~km}$ ( 10 in 2015,100 in 2016, 57.4 in 2017, 53.6 in 2018, 45.7 in 2019 and 39.3 in 2020).

5. Huerto-Animado (El Marquesado, Cádiz, 36.443999, $-6.121109)$. This is a low-intensity organically cultivated area (1.7 ha in size) composed of fruit trees and orchards combined with seasonal vegetables in a typical heterogeneous mosaic-like landscape. The transect (length $=0.57 \mathrm{~km}$ ) was divided into 4 sections that runs through different crops in the area. Field work was carried out 1-4 times per month from July 2014 to December 2015. There was no field work in 2016 due to a change in the use of the plot by the owner. The total distance covered in the BMS censuses was $31 \mathrm{~km}$ (9.5 in 2014 and 21.7 in 2015).

6. Econatura (El Marquesado, Cádiz, 36.460587, -6.117672). As Huerto Animado, this is a low-intensity organically cultivated area $(2.4$ ha in size). The transect (length $=0.92 \mathrm{~km}$ ) was divided into 4 sections that runs through different crops in the area. Field work was carried out 2-6 times per month from April 2016 to December 2020. The total distance covered in the BMS censuses was $194 \mathrm{~km}$ (37 in 2016, 40 in 2017, 37 in 2018, 43 in 2019 and 35 in 2020).

7. Cerro (Cerro de los Mártires, San Fernando, Cádiz $36.460587,-6.212443)$ is a park-like area composed of Pine trees (Pinus spp.) and other Mediterranean scrubland species (e.g. Pistacia lentiscus L.). The transect (length $=0.6 \mathrm{~km}$ ) was divided into 2 sections. Field work was carried out 1-4 times per month from August 2014 to December 2020. The total distance covered in the BMS censuses was $240 \mathrm{~km}$ ( 5 in 2014, 34 in 2015, 58 in 2016, 46 in 2017, 40 in 2018, 27 in 2019 and 26 in 2020).

\section{Data analyses}

For each site, the numbers of butterflies recorded during BMS censuses and the distances walked per month were pooled. An abundance index based on the number of butterflies recorded per kilometre and month was then calculated. The total distance walked in BMS censuses was 4,184 km. Butterfly abundances during March and April 2020 might be underrepresented due to COVID19 movement restrictions.

\section{Reproductive behaviour}

As in other Nymphalidae, the reproductive behaviour of $\mathrm{Va}$ nessa cardui is very conspicuous: males are territorial and defend certain patches against other intruding males while systematically courting females. In a typical patch defence sequence, a male settles on bare ground with both wings in a typical V-shape and waits for other butterflies to arrive. In some cases, other structures (e.g. a pole, a small stone or a tree a few meters above the ground) were used as perches. Territorial males prefer sunny, west-oriented open areas close to linear structures (such as fences, pathways or lines of trees, see also Bitzer, 1995; Bitzer \& Shaw, 1979; Myers et al., 2013; M. Cuadrado, pers. observ.).

Territorial males exhibit a well-defined behaviour against other males: two males circling closely around each other while ascending for a few seconds that ends with one of them flying away (cf. Bitzer, 1995; Bitzer \& Shaw, 1979; Stefanescu, 2001, see also Brown \& Alcock, 1990; Cuadrado, 2017 for a description of this behaviour in red admiral butterflies, Vanessa atalanta Linnaeus, 1758). In some cases, the intruder attacked the territorial male, which immediately flew away. The winner always returned to the same patch. If not visited by another butterfly, the male often performs a short patrolling ellipse-shaped flight at a low altitude $(<3$ $\mathrm{m}$ height) prior to returning to the same perch.
Females elicit courtship and males follow them flying up-anddown close-by near the ground. After that, the female usually lands on the ground and the male settles beside her, sometimes touching her with his antennae and attempting to mate (cf. Bitzer, pers. commun.; M. Cuadrado, pers. observ.). Males are territorial and mate a few hours before sunset (see also Brown \& Alcock, 1990; Cuadrado, 2017 for similar behaviour in Vanessa atalanta).

The reproductive behaviour of painted ladies during BMS censuses were noted. The territorial-defence exhibited by males was recorded for a maximum of $10 \mathrm{~min}$. The variables used to define male territorial behaviour were: (1) number of males recorded defending a territory during each BMS transect, (2) number of butterflies and the species that were involved in ascending flying circles (see above), and (3) other reproductive-related behaviour. Egg-laying females, eggs or larvae of Vanessa cardui were also recorded. Stefanescu et al. (2011) report standard sampling protocols for detecting immature stages in the field. In this study however, these protocols were not used as the number of females recorded ovipositing, the numbers of larvae and pupae were remarkably small (see Results).

\section{RESULTS}

\section{Adult year-round phenology}

A total of 2341 painted ladies (or 0.56 butterflies $/ \mathrm{km}$ ) were recorded during the BMS censuses (data for all years and sites pooled). The number of butterflies varied greatly between years. They were very abundant in $2019(\mathrm{~N}=$ 1245 , or 1.8 butterflies $/ \mathrm{km}$ ), much less abundant in 2015 , 2016 and 2018 ( $>0.3$ butterflies $/ \mathrm{km})$ and remarkably few in 2014, 2017 and $2020(<0.2$ butterflies $/ \mathrm{km})$. Overall, the average number recorded during BMS transects per year was $0.49+0.61$, range $=0.05-1.79, \mathrm{~N}=7$ years).

The year-round abundance based on the number of painted lady butterflies recorded each month showed a typical multimodal distribution with up to 3-4 well defined periods of abundance throughout a year (Fig. 1). When year 2019 is excluded, painted ladies were more abundant in February, May and October (Fig. 1). In 2019 however, the year-round abundance of butterflies was remarkably different from that recorded in the other 6 years (Fig. 1). Our results show that painted ladies (1) were more abundant in February, July and October; (2) were absent during spring (April-June 2019); (3) the number of butterflies and their abundance were exceptionally high $(1,245$ butterflies in $690.3 \mathrm{~km}$, or 1.8 butterflies $/ \mathrm{km}$ ); (4) most of these butterflies were recorded between July 1 and 13, 2019 (977 butterflies in $51.4 \mathrm{~km}$, or 19 butterflies $/ \mathrm{km}$ ) and (5) the abundance (butterflies $/ \mathrm{km}$ ) was remarkably high along some transects (e.g. 100.5 on 1-VII-19 and 57.3 on 3-VII19, both at Punta del Boquerón, 32.6 on 1-VII-19 at Camposoto or 7.5 on 5 -VII-19 at Econatura). In other words, many more butterflies were recorded during the two weeks of July 2019 than during the rest of the study, when the data for all sites and all years was pooled. These figures indicate the occurrence of a spectacular and unique migration across the study area in July 2019. According to information published by the press, the same phenomena was reported at other sites in Spain and was subsequently recorded in other European countries a few weeks later. A similar migration was recorded in 2009 and for that reason, 


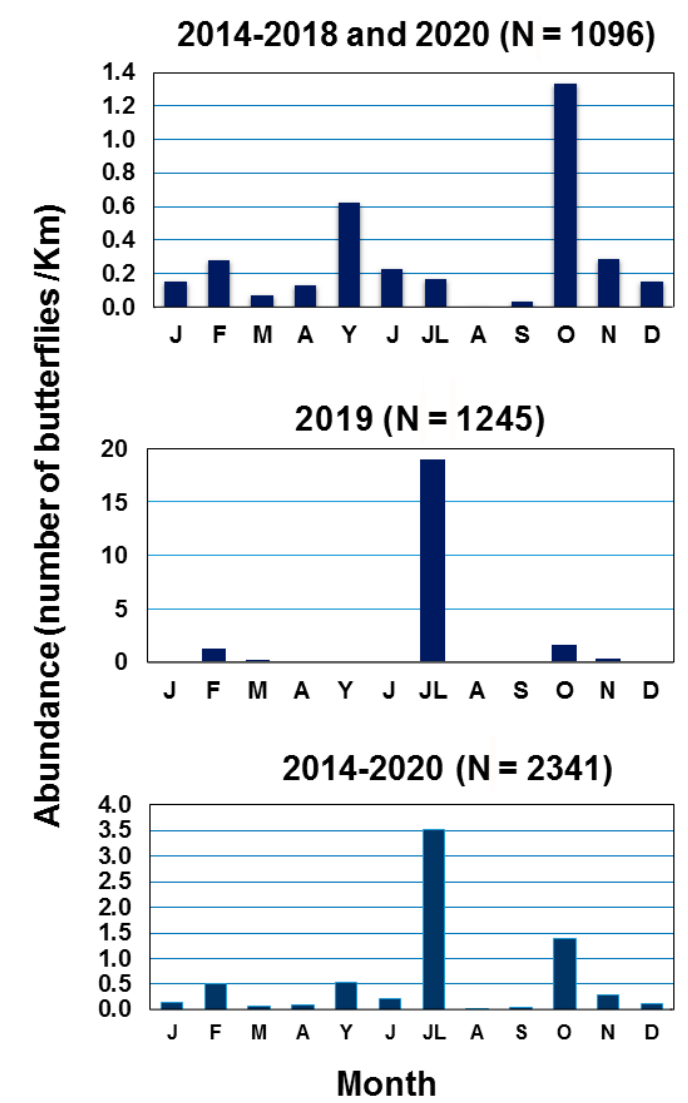

Fig. 1. Monthly records of the abundance of painted lady butterflies recorded in three different periods: years 2014-2018 and 2020 (top figure), 2019 (middle) and 2014-2020 (bottom). Abundance is the average number of butterflies recorded per $\mathrm{km}$ per year based on the BMS (Butterfly Monitoring Scheme, cf. Van Swaay et al., 2012). Data for the seven sites studied (see methods) were pooled. The total number of butterflies recorded during each period is also included.

the Media defined it as a "once-in-a-decade Painted lady massive migration" (see Cuadrado, 2019 for more details).

When the 2019 data is not included, there is a clear yearround pattern in abundance with three peaks (Fig. 1): one in winter (up to February), another in spring (up to May) and finally, one in autumn (up to October). Similarly, the peak of abundance is usually higher in autumn than in spring, with a minimum in winter (Fig. 1). We consider this to be a realistic year-round phenology for this species in the study area.

\section{Dates of the peaks in abundance}

Fig. 2 shows the distribution of the numbers of butterflies in the three different periods of the year when they were most abundant (winter, spring and autumn). In winter, this butterfly was most abundant in mid- and late February. On some days, the abundance (butterflies $/ \mathrm{km}$ ) was relatively high (e.g. 20.1 on 21-II-16 at Camposoto, 11.9 on 17-II-19 at Econatura, 11.6 on 24-II-16 at Cerro, 9.2 on 16-II-19 at Camposoto, 6.2 on 16-II-19 at Botánico and 5.9 on 16-II19 at Punta del Boquerón). In spring, they were most abundant in late May. On some days, the abundance (butterflies/ $\mathrm{km}$ ) was relatively high (e.g. 23.4 on $25-\mathrm{V}-15$ at Punta del Boquerón, 16.9 on 30-V-16 at Punta del Boquerón or 16.6

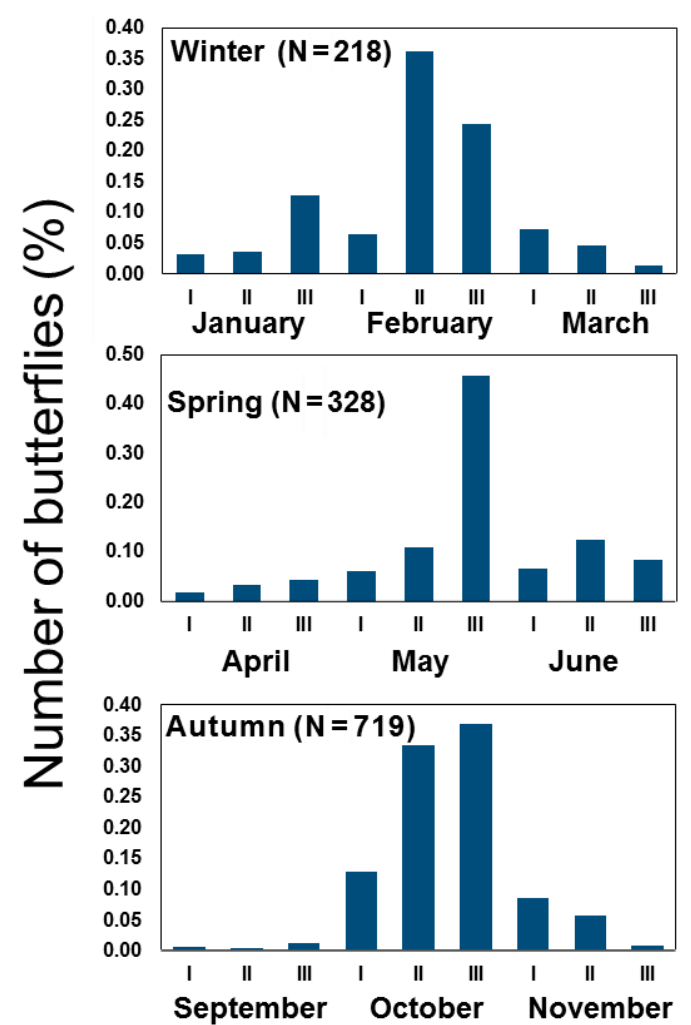

Fig. 2. Number of painted lady butterflies recorded each year in winter (January-March), spring (April-June) and autumn (September-November). The numbers in three periods of 10-days were recorded in each month (I: between days 1-10, II: days 11-20 and III: days $21-30$ or 31). Data for all the sites studied and years (2014-2020) were pooled. The total overall number of butterflies recorded during each period is also included.

on $26-\mathrm{V}-15$ at Cerro). In autumn, they were most abundant in mid- and late October. On some days, the abundance (butterflies $/ \mathrm{km}$ ) was remarkably high (e.g. 140.2 on 29 -X16, 22.9 on 14-X-19 at Camposoto, 69.4 on $30-\mathrm{X}-16$ and 77.7 on 31-X-16 at both Camposoto, 23.9 on $16-\mathrm{X}-19$ and 21.7 on $17-\mathrm{X}-19$ at Econatura, 15.2 on $25-\mathrm{X}-18$ and 16.6 on 15-XI-18 at Camposoto, 15.2 on 17-X-18 at Econatura and 5.0 on 12-X-18 at Punta del Boquerón).

\section{Year to year differences}

Fig. 3 shows the year-to-year difference in the abundance of these butterflies recorded during the different periods of the year when they were most abundant (winter, spring and autumn). This species was most abundant in winter 2016 and 2019, in spring 2015 and autumn 2016. Its abundance varied greatly from one year to another in winter, spring and autumn.

\section{Reproduction in Vanessa cardui}

A total of 49 males were recorded in the field exhibiting typical territorial behaviour (excluding 2014): 5 in 2015, 18 in 2016, 2 in 2017, 13 in 2018, 5 in 2019 and 6 in 2020 in autumn-winter (Fig. 4). The maximum number was recorded in October and decreased greatly in the midwinter months (December-January) and another peak was recorded in February. A total of 170 male-male interactions were recorded. Of them, $137(80.0 \%)$ was between two or 


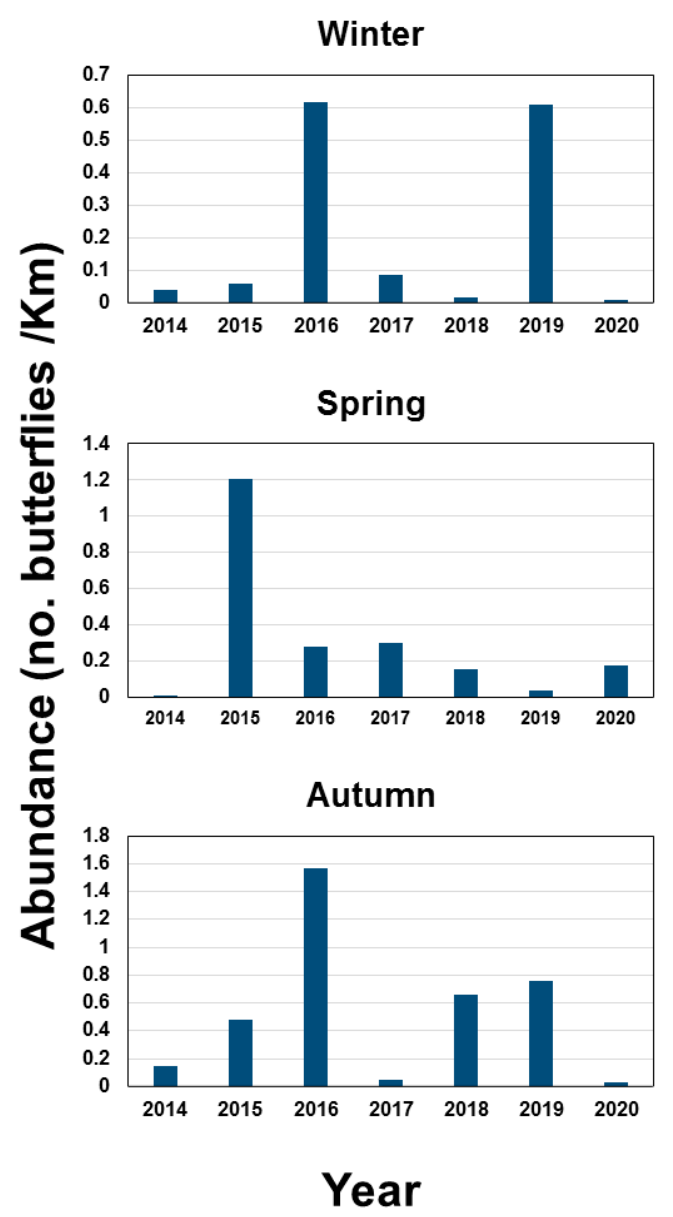

Fig. 3. The abundance of painted lady butterflies recorded each year in winter (January-March), spring (April-June) and autumn (September-November). Data for the seven sites studied were pooled.

more painted lady butterflies. In the remaining $33(20.0 \%)$, another species was involved. Most of the time, the other species was the red admiral butterfly (Vanessa atalanta), which is also territorial in this area (see e.g. Bitzer \& Shaw, 1979; Cuadrado, 2017) and exhibits the same territorial behaviour of an ascending circular flight.

Furthermore, 17 attacks of a territorial male on (and eviction) other species were recorded: Vanessa atalanta $(\mathrm{N}=8)$, Vanessa cardui $(\mathrm{N}=3)$, Pieris rapae $(\mathrm{N}=3)$, Pieris brassicae $(\mathrm{N}=1)$, Pararge aegeria $(\mathrm{N}=1)$ and Sympetrum fonscolombii (Odonata, $\mathrm{N}=1$ ). Finally, 11 females were observed ovipositing ( 7 in October at three sites, 2

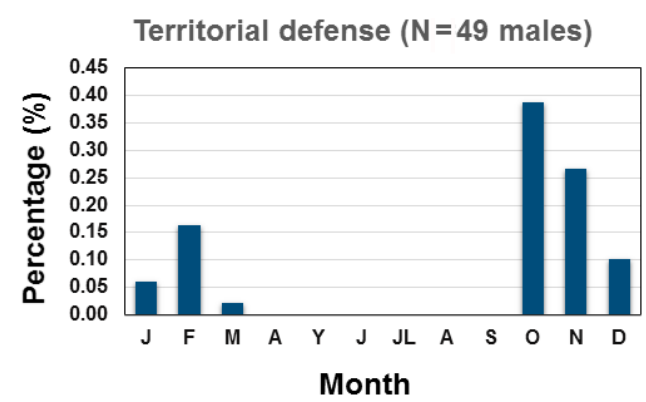

Fig. 4. Percentage of male painted lady butterflies that exhibited territory behaviour. Data for all the years and sites were pooled. in November at two sites, 1 in December and 1 in April), one mating (date 31 October 2016 at Camposoto) and one chrysalis in October 2019 at Camposoto.

\section{DISCUSSION}

The year-round phenology recorded in this study agrees with the reports that this species migrates north in spring and south in autumn in the Palearctic (see introduction for references). The results presented indicate (1) the progressive arrival of migrants from northern latitudes in autumn (from September to November, with a well-defined peak in October); (2) low numbers during mid-winter (December-January) followed by (3) a slight increase in numbers in late winter (February); (4) another peak in abundance in spring (mainly May) contemporary with the northward movement of butterflies, and finally (5) a steady decrease from June onwards, indicating that this butterfly leaves this area in summer (July and August), the months when this species is rare or absent.

However, although this was the general year-round phenology recorded for painted lady butterflies at the sites studied (see also Stefanescu et al., 2013, 2016, 2021; Talavera \& Vila, 2016; Talavera et al., 2018; Comay et al., 2020 for similar results), there were marked site-to-site and year-to-year differences. For instance, in 2019 a massive migration occurred, which was bigger than any previously recorded in this area. The occurrence of massive migrations of this species is a well-known and recorded many times (see for instance Myers, 1983; Stefanescu et al., 2013; Benyamini, 2017 and references therein, see Hu et al., 2021 for a review). At the sites studied, this event was exceptional in many ways: (1) the species was rare from March to June 2019 and there was no spring migratory peak; (2) the peak in migration occurred in early July (very late in the season) and more importantly, (3) the number of butterflies recorded along the BMS transects was exceptionally high (ca. 50 times higher than usual). This is similar to the massive spring migration that occurred in 2009 (e.g. Moreno Benítez, 2010; Stefanescu et al., 2011, 2013; Menchetti et al., 2019). The same massive migration was recorded a little latter in other European countries in 2019, which indicates these butterflies were migrating north (see Cuadrado, 2019 and references therein). The geographical origin of these butterflies and why they were so abundant, however, is still unknown (but see below). Accepting that the year-round phenology recorded in 2019 is not typical of this species the current study provides a comprehensive description of the year-round phenology of this butterfly in a southern European habitat.

\section{Assessing year-round phenology at the sites studied}

This study provides detailed information on the timing of autumn migration of painted lady butterflies at a European site (see also Fernández Haeguer \& Jordano Barbudo, 1982). Autumn migration occurred every year between September and November with a distinct peak in migration in mid-October. Unlike the spring migration (see below), the occurrence of this butterfly in autumn was highly pre- 
dictable, usually it occurred in one, or sometimes, two waves with some differences depending on year and site. Stefanescu et al. (2017) provide a good phenological description of the timing of the autumn migration in Morocco and Algeria. The results presented coincide with these findings as the arrival of this species in North Africa occurs around the same dates, but with a small delay (i.e. late October-November, cf. Stefanescu et al., 2017).

As expected from their migratory habits, the butterflies recorded in autumn are true migrants as they are not of local origin. There are a number of factors that support this idea. Firstly, immatures or butterflies were largely absent in the area in late summer (August and most of September), an argument similar to that of Stefanescu et al., (2017). Secondly, high temperatures and extremely dry conditions during long Mediterranean summers (see e.g. Font Tullot, 1983) limit the development of herbaceous plants, which the larvae feed on (see Obregón \& Prunier, 2014 for a description of the plants fed on by this species at Mediterranean sites). Thirdly, most of the migrants recorded in autumn had worn wings (assigned wing score $>2 \mathrm{cf}$. Stefanescu et al., 2017, M. Cuadrado, pers. observ.). Fourthly, in some years, these butterflies arrived in the area in exceptionally high numbers (see e.g. Camposoto, 2016). Although some of those recorded in autumn could also have a local origin (e.g. from breeding populations recorded at higher altitude sites in the Mediterranean area), the number reproducing in the area was very low, which means that it contributed very little to the autumn migration.

Although the final destination of most autumn migrants is probably Africa (Morocco and North Africa according to Stefanescu et al., 2017 or the sub-Saharan Africa according to Talavera \& Vila, 2016), some remained throughout autumn and winter at the sites studied and reproduced there each year. The number was however, remarkably low (see also Stefanescu et al., 2013 for similar findings in Morocco).

Those that remained in the area during autumn started to breed immediately upon arrival in October and continued reproducing throughout winter until the beginning of March. The reproductive activity however, decreases with time as the number of butterflies decline during winter. Common reproductive behaviour, such as, territorial defence, courtship and egg-laying, in addition to eggs, larvae and pupae, were recorded. Among them, patch-defence and "hill-topping" behaviour (Bitzer \& Shaw, 1979; Brown \& Alcock, 1990; Bitzer, 1995; Stefanescu, 2001; Cuadrado, 2017) were the most conspicuous during these months. This is also reported for red admiral butterflies (Cuadrado, 2017), which defend patches a few hours before sunset (see also Brown \& Alcock, 1990; Talavera \& Vila, 2016; Stefanescu, pers. comm.). Moreover, painted lady and red admiral butterflies (another migratory Nymphalid species that reproduces in the same areas in the same season, cf. Cuadrado, 2017) showed a strong preference for these areas to exhibit patch-defence and hill-topping behaviour in autumn and winter. For this reason, intra- and interspecific interactions were often recorded. In some cases, up to 5 ( 4 cardui and 1 atalanta) or 4 ( 3 cardui and 1 atalanta) butterflies were recorded performing the typical ascending close circling flights during field work (see Results). The preference showed by both Vanessa species for these specific patches in autumn and winter deserve further studies, as there are other resident species (e.g. Old-World swallowtails Papilio machaon and Iphiclides feisthamelii, cf. Cuadrado, 2016 and the speckled wood butterfly, Pararge aegeria) that use the same spots while defending a patch during their reproduction in spring and summer (M. Cuadrado, pers. observ.). Furthermore, this study also provides convincing evidence of the reproduction of painted lady butterflies in autumn and winter at a European location. This is repeatedly reported in a number of studies (e.g. Stefanescu et al., 2013; Menchetti et al., 2019), but to my knowledge, this is the first time that it is reported in detail.

From January to July, the number of painted lady butterflies recorded showed two distinct peaks in abundance (one in winter and another in spring). In winter, they were more abundant in mid- late February every year. The origin of these butterflies is unclear. Although some of the butterflies recorded in February could also have been of local origin (i.e. those that reproduce throughout the season), the number breeding in autumn and winter was very low, which means that its contribution to the winter peak in abundance is certainly negligible. Available evidence indicates that most butterflies recorded in mid- and late-February are migrants moving north to reproduce. Firstly, $\mathrm{Hu}$ et al. (2021) strongly suggest that those recorded in February are part of the northward movement of migrant butterflies of a subSaharan Africa origin (the most likely areas and migratory trajectories are reported in $\mathrm{Hu}$ et al., 2021: 6). Secondly, the study of the geographical origin of butterflies using stable hydrogen isotope composition values $\left(\delta^{2} \mathrm{H}\right)$ of butterfly wings have provided some cues about the origin of these populations (e.g. Brattström et al., 2010; Stefanescu et al., 2016, 2017; Talavera et al., 2018). This technique provides good evidence of the origin of butterflies (i.e. the geographical areas where the larvae developed). According to these authors, the geographical origin of painted lady butterflies found in late February in the Mediterranean area is Morocco (cf. Stefanescu et al., 2011) or even further south, in sub-Saharan Africa (Talavera et al., 2018). And thirdly, these findings are also supported by the record of a mass emergence of this butterfly at different African sites in winter (e.g. Israel cf. Benyamini, 2017 and Lanzarote cf. Stefanescu et al., 2011) or March (e.g. Sudan and Algeria cf. Stefanescu et al., 2011). Thus, the butterflies recorded at the sites studied in February could be butterflies that reproduced further south during their northward migration as well as locally, which emerged after breeding in winter. The importance of local and non-local populations of this butterfly for the winter peak in abundance at the sites studied deserves further study.

Similarly, the peak in abundance recorded in spring (mainly late May) coincides with the northern movement of butterflies after reproducing further south. These butterflies are not of local origin as this species does not breed 
here during spring. Unlike the autumn migration, the spring migration was not predictable: it remained undetected for several years, abundance peaks were unclear or on the contrary, the number of butterflies recorded was remarkably high (e.g. year 2015, see results, see also $\mathrm{Hu}$ et al., 2021). Unlike the autumn migration, the spring migration is recorded at other Mediterranean sites (see for instance, Hu et al., 2021), at approximately the same time: Gibraltar, May $10-20^{\text {th }}$ (Bensusan et al., 2014), Córdoba, May 15-16 $6^{\text {th }}$ (Fernández Haeger \& Jordano Barbudo, 1982) and Menorca, May 15-30 ${ }^{\text {th }}$ (Stefanescu \& Colom, 2018).

\section{Year-to-year and site-to-site differences in the abundance of painted lady butterflies}

This study reports a relative complex phenology with great differences in the abundance of butterflies in different seasons of the same year and also between years and sites (see also Benyaminy, 2017; Comay et al., 2020, for similar findings). At the sites studied, both autumn and winter migrations were predictable and occurred, with slight differences, on the same dates each year. In contrast, the spring migration was either not recorded every year or the number of butterflies recorded was very high (see above). Furthermore, unlike other studies carried out at different Mediterranean sites (e.g. Fernández Haeger \& Jordano Barbudo, 1982; Stefanescu \& Colom, 2018; Comay et al., 2020), they were more abundant at the sites studied in autumn than in spring, which indicates the importance of coastal sites in the southern Mediterranean for the migration of this species.

There is another important aspect that should be considered. An active migration, i.e. "a notably persistent, undistracted and straightened out (or directional) movement", cf. Dingle \& Drake (2007: 114) was not recorded in spring or autumn. That is, the butterflies were recorded while basking, resting directly on the ground or actively feeding and moving nervously among flowers of Dittrichia viscosa, Echium plantagineum, Limoniastrum monopetalum and Acacia saligna, which are a source of nectar and very common in the area (see also Cuadrado, 2019). As patch defence or hill-topping behaviour were recorded for only a few butterflies in autumn and winter, it is likely that most butterflies use the areas studied as stop-over sites during their year-round migratory trips (see also Bensusan et al., 2014; Stefanescu et al., 2017 for similar results in spring).

Furthermore, in an inspiring paper Stefanescu et al., (2021) present an analysis of the influence of timing of mating, reproductive status and resource availability in relation to the reproductive cycle of painted lady butterflies and their migration throughout the Palearctic. In that paper, the authors tested the "oogenesis-flight syndrome" a hypothesis that posits that migration and reproduction cannot occur at the same time in migrant insects, and in the case of painted lady butterflies, migration occurs prior to reproduction. In the population studied, reproduction of migrants in spring was not recorded, which is in accordance with the oogenesis-flight syndrome. Similarly, the same also applies to the autumn migration with an important difference: although most of the butterflies continue their migration south, a few ended their migration at the sites studied, remaining and reproducing there in autumn and winter. Thus, most of the butterflies recorded at the sites studied were true migrants that reproduce somewhere else.

In a recent paper, Hu et al. (2021) provide some cues on the causes of the annual fluctuations in the populations of painted lady butterflies recorded in the Western Palearctic. These authors used the normalized difference vegetation index (NDVI) as a measure of the food available for immatures (especially, the larval host plants). The abundance of this butterfly in Western Europe is a combination of three factors: (1) high winter NDVI in the Savanna/Sahel in sub-Saharan Africa in winter, (2) high spring NDVI in the Maghreb in North Africa and (3) favourable tailwinds during migration. Therefore, the abundance this butterfly in Western Europe in spring is a combination of good environmental conditions (especially, the NDVI indices recorded in North Africa in early spring and sub-Saharan Africa in winter) and favourable tailwinds during migration. These findings also indicate that this butterfly must be able to cross the Sahara Desert, which is remarkable achievement for an insect (Menchetti et al., 2019; Hu et al., 2021).

This study describes for the first time the timing of the autumn migration and reproduction of painted lady butterflies in autumn and winter months for a European population. To date, the migratory route of this butterfly in autumn is unknown due to the fact that standard BMS butterflies counts cease in late summer (e.g. September, cf. Stefanescu \& Colom, 2018; Hu et al., 2021). The findings reported highlight the importance of carrying out butterfly counts in late-winter and autumn, especially at sites in southern Europe.

Secondly, these butterflies use the same migratory pathways and same areas for breeding in autumn and winter although the numbers fluctuate enormously, most probably due to changes in the availability of food and local ambient temperatures (cf. Stefanescu et al., 2011).

Thirdly, the location of the areas studied, at the southern tip of Western Europe close to North Africa, is on an important migratory pathway for this species in the Palearctic (see also Stefanescu et al., 2013, Benyamini, 2017).

And fourthly, although it is assumed that in their migration they use high-altitude favourable African tailwinds (see Stefanescu et al., 2007, 2013; Hu et al., 2021 and references therein), they use the same areas year after year as stop-over sites (this study), especially lowland sites near the coast line (also reported by Benvenutti et al., 1996; Stefanescu et al., 2011) where they feed on nectar, which fuels their remarkably long migration.

ACKNOWLEDGEMENTS. This study depended on the Spanish Butterfly Monitory Scheme (BMS) network, which is coordinated by M. López Munguira. R. Fernández Zamudio, who supplied the permits to carry out the field work. I am grateful to C. Stefanescu for constructive and always helpful discussions on the migration of the painted lady butterfly. Together with an anonymous referee, C. Stefanescu provided many useful comments on early drafts of this paper. C. Fernández kindly checked the English. This study was carried out without any type of financial support. 


\section{REFERENCES}

Bensusan K.J., Nesbit R., Pérez C.E., Tryjanowski P. \& ZduNIAK P. 2014: Species composition and dynamics in abundance of migrant and sedentary butterflies (Lepidoptera) at Gibraltar during the spring period. - Eur. J. Entomol. 111: 555-559.

Benvenuti S., Dall'antonia P. \& Ioalè P. 1996: Directional preferences in the autumn migration of the Red Admiral (Vanessa atalanta). - Ethology 102: 177-186.

BENYAMINI D. 2017: A swarm of millions of Vanessa cardui (Linnaeus, 1758) in winter-spring 2015-2016 in the south-east Mediterranean - the missing link. — Atalanta 48: 103-128.

BitZer R.J. 1995: Territorial Behavior of the Red Admiral Butterfly, Vanessa atalanta (L.) (Lepidoptera: Nymphalidae). $\mathrm{PhD}$ thesis, Iowa State University, $227 \mathrm{pp}$.

BITZER R.J. 2016: The Red Admiral and Painted Lady Research. URL: http://vanessa.ent.iastate.edu/

Bitzer R.J. \& Shaw K.C. 1979: Territorial behavior of the Red Admiral, Vanessa atalanta (L.) (Lepidoptera: Nymphalidae). —J. Res. Lepid. 18: 36-49.

Brattström O., Bensch S., Wassenaar L.I., Hobson K.A. \& ÅKESSON S. 2010: Understanding the migration ecology of European red admirals Vanessa atalanta using stable hydrogen isotopes. - Ecography 33: 720-729.

Brown W.D. \& Alcock J. 1990: Hilltopping by the Red Admiral butterfly: mate searching alongside congeners. - J. Res. Lepid. 29, 1-10.

Chapman J.W. \& Drake V.A. 2010: Insect migration. In Breed M.D. \& Moore J. (eds): Encyclopaedia of Animal Behavior. Vol. 2. Oxford Academic Press, Oxford, pp. 161-166.

Chowdhury S., Fuller R.A., Dingle H., Chapman J.W. \& Zaluck M.P. 2021. Migration in butterflies: a global review. - Biol. Rev. 96: 1462-1483.

Comay O., Ben Yehuda O., Benyamini D., Schwartz-Tzachor R., Pe’er I., Melochna T. \& Pe'er G. 2020: Analysis of monitoring data where butterflies fly year-round. - Ecol. Appl. 30(8): e02196, 17 pp.

Cuadrado M. 2016: Número de generaciones (voltinismo) en varias especies de mariposas diurnas en una población de Jerez de la Frontera (Cádiz). — Rev. Soc. Gadit. Hist. Nat. 10: 27-31.

CuAdRADO M. 2017: The year-round phenology of the migratory Red Admiral Vanessa atalanta L. (Lepidoptera: Nymphalidae) in a Mediterranean area in southern Spain. - Eur. J. Entomol. 114: 517-525.

Cuadrado M. 2019: Invasión de mariposas carderas en las costas de Cádiz. - Quercus 404: 30-36.

Dingle H. \& Drake V.A. 2007: What is migration? — Bioscience 57: $113-121$.

Fernández Haeger J. \& Jordano Barbudo P. 1982: Observaciones sobre una migración de Cynthia cardui (L.) en la provincial de Córdoba. - Graellsia 38: 189-192.

Font Tullot I. 1983: Climatología de España y Portugal. Instituto Nacional de Meteorología, Madrid, 296 pp.

Holland R.A, Wikelski M. \& Wilcove D.S. 2006: How and why do insects migrate? - Science 313: 794-796.

Hu G., Stefanescu C., Oliver T.H., Roy D.B., Brereton T., Van SwaAy C., Reynolds D.R. \& Chapman J.W. 2021: Environmental drivers of annual population fluctuation in a trans-Saharan insect migrant. - Proc. Natl. Acad. Sci. U.S.A. 118: 1-11.

Menchetti M., Guéguen M. \& Talavera G. 2019: Spatio-temporal ecological niche modelling of multigenerational insect migrations. - Proc. R. Soc. (B) 286: 20191583, 9 pp.

Moreno Benítez J.M. 2010: Grandiosa migración de la mariposa de los cardos en Málaga. — Quercus 289: 43.
MYERs M.T. 1983: A southward return migration of Painted lady butterflies Vanessa cadui, over southern Alberta in the fall of 1983, and biometerorological aspects of their outbreaks into North America and Europe. - Can. Field Nat. 99: 147-155.

Myers P., Espinosa R., Parr C.S., Jones T., Hammond G.S. \& Dewey T.A. 2013: Vanessa atalanta. URL: http://animaldiversity.org/accounts/Vanessa_atalanta/ (last accessed 30 Jan 2017).

Nesbit R.L., Hill J.K., Worwood I.P., Siwell D., Bensusan K.J. \& Chapman J.W. 2009: Seasonally adaptive migratory headings mediated by a sun compass in the painted lady butterfly Vanessa cardui. - Anim. Behav. 78: 1119-1125.

Obregón R. \& Prunier F. 2014. Diversidad y ecología de una comunidad de Papilionoidea (Lepidoptera) en el arroyo Pedroches y su entorno: un paraje natural periurbano a conservar (Córdoba, España). — Revta Gadit. Entomol. 5: 183-201.

Opler P.A. \& KrizeK G.O. 1984: Butterflies East of the Great Plains. Johns Hopkins University Press, Baltimore, 322 pp.

Pollard E., van SwaAy C.A.M., Stefanescu C., Lundsten K.E. \& MAes D. 1998: Migration of the painted lady butterfly Cynthia cardui in Europe: evidence from monitoring. - Divers. Distrib. 4: 243-253.

STEFAnESCU C. 2001: The nature of migration in the red admiral butterfly, Vanessa atalanta: evidence from the population ecology in its southern range. - Ecol. Entomol. 26: 525-536.

Stefanescu C. \& Colom P. 2018: Análisis del impacto del cambio global sobre las poblaciones de mariposas de Menorca. BIOCLIMA Menorca. Conocimiento, capacitación y difusión de los efectos del cambio climático sobre la biodiversidad en la Reserva de la Biosfera de Menorca. Observatori Socioambiental de Menorca, Informe técnico, $71 \mathrm{pp}$.

Stefanescu C., Alarcón M. \& Ávila M. 2007: Migration of the painted lady butterfly, Vanessa cardui, to north-eastern Spain is added by African wind currents. - J. Anim. Ecol. 76: 888-898.

Stefanescu C., Alarcón M., Izquierdo R., Páramo F. \& Ávila A. 2011: Moroccan source areas of the painted lady butterfly Vanessa cardui (Nymphalidae: Nymphalinae) migrating into Europe in spring. - J. Lepid. Soc. 65: 15-26.

Stefanescu C., Páramo F., Åkesson S., Alarcón M., Ávila A., Brereton T., Carnicer J., Cassar L.F., Fox R., Heliölä J., Hill J.K., Hirneisen N., KJellén N., KüHn E., KuUsSaAri M., Leskinen M., Liechti F., Musche M., Regan E.C., Reynolds D.R., Ryrholm N., Schmaljohann H., Settele J., Thomas C.D., van SWAaY C. \& ChapMAn J.W. 2013: Multi-generational long-distance migration in insects: studying the painted lady butterfly in the Western Palaearctic. - Ecography 36: 474-486.

Stefanescu C., Soto D.X., Talavera G., Vila R. \& Hobson K.A. 2016: Long-distance autumn migration across the Sahara by painted lady butterflies: exploiting resources pulses in the tropical Savannah. — Biol. Lett. 12: 20160561, 4 pp.

Stefanescu C., Puig-Montserrat X., Samraoui B., Izquierdo R., Ubach A. \& Arrizabalaga A. 2017: Back to Africa: Autumn migration of the painted lady butterfly Vanessa cardui is timed to coincide with an increase in resource availability. - Ecol. Entomol. 42: 737-747.

Stefanescu C., Ubach A. \& Wiklund C. 2021: Timing of mating, reproductive status and resource availability in relation to migration in the painted lady butterfly. - Anim. Behav. 172: $145-153$.

Suchan T., Talavera G., Sáez L., Ronikier M. \& Vila R. 2019: Pollen metabarcoding as a tool for tracking long-distance insect migrations. - Mol. Ecol. Resour. 19: 149-162.

Talavera G. \& Vila R. 2016: Discovery of mass migration and breeding of the painted lady butterfly Vanessa cardui in the 
Sub-Sahara: the Europe-Africa migration revisited. - Biol. J. Linn. Soc. 120: 274-285.

Talavera G., Bataille C., Benyamini D., Gascoigne-Pees M., \& VILA R. 2018: Round-trip across the Sahara: Afrotropical Painted Lady butterflies recolonize the Mediterranean in early spring. - Biol. Lett. 14: 20180274, 4 pp.

Van SwaAy C.A.M., Brereton N T., KirKLANd P. \& Warren M.S. 2012: Manual for Butterfly Monitoring. Report VS2012.010. De Vlinderstichting/Dutch Butterfly Conservation, Butterfly
Conservation UK and Butterfly Conservation Europe, Wageningen, $12 \mathrm{pp}$.

Williams C.B. 1930: The Migration of Butterflies. Oliver and Boyd, Edinburgh, 473 pp.

Williams C.B. 1957: Insect migration. - Annu. Rev. Entomol. 2: $163-180$

Received April 11, 2021; revised and accepted September 9, 2021 Published online September 29, 2021 